\title{
PRODUCT-SERVICE SOLUTION INVENTORY RECORD FOR MALAYSIAN PALM OIL ARGIBUSINESS
}

\author{
Zaitun Zainal Abidin ${ }^{1}$ and Siti Zubaidah Ismail ${ }^{1 *}$
}

\section{*Correspondence \\ zubaidahismail@ump.ed u.my \\ ${ }^{1}$ Faculty of Mechanical and Manufacturing Engineering, Universiti Malaysia Pahang, 26600, Pekan, Pahang, Malaysia}

Articles Info: Received 29 January 2020

Received in revised form 26 March 2020 Accepted 27 March 2020

Available online 31 March 2020

Keywords:

Product-service system; Inventory Control; Palm Oil plantation; Inventory Record

\begin{abstract}
Product-Service System (PSS) inventory control for Palm Oil Plantation Company and developing one software application named as inventory record to help the management for managing the inventory control of the company. This research deals with the study of PSS and inventory control at Company A which is a Malaysian palm oil plantation company. The aims of this research are to describe and analyze how Product-Service Solution Inventory. The palm oil industry is one of the well-known industries in Malaysia that provide the most prominent contribution to Malaysia's economy. PSS is a managing system that combining product and service in one system. PSS could not be running smoothly when the inventory of product and service are managed in separate interface systems which is by using manual inventory control like Microsoft Excel and handwriting documentation. In order to make PSS inventory control easier, and systematic, an inventory application system is developed. This research is focusing on developing PSS inventory record for fertilizer and pesticide at the Company A. This record will be using Microsoft Visual Basic 6 which could help in decision and calculation making for product and service of palm oil plantation.
\end{abstract}

\section{INTRODUCTION}

The palm oil industry is one of the regulated industry in Malaysia. The oil palm and the palm oil industry become a great economic that give more benefit to Malaysia where the current production of 19 million metric tons of Crude Palm Oil and adds $8 \%$ to the country's Gross Nation Income (GNI) according to Malaysia Palm Oil Council (MPOC). In the oil palm cultivation, fertilizing is the single large cost value about $60 \%$ of the upkeep cost. In fact, it constituted fertilizer alone made up about $24 \%$ of the total production cost of oil palm in Malaysia. Fertilizer is an important input in oil palm plantations and has to be managed efficiently for maximum return.

A product-service system (PSS) can be defined as one system that helps to satisfy the specification of the customer needs and to provide better environmental impact compared with the traditional business models. PSS also is an excellent tool to improve competitiveness and to promote sustainability at the same 
time. PSS business models enable companies to form new sources of added value and competitiveness, as long as they meet the customer needs in an integrated and suitable way. PSS comprises combine and design for a tangible product, and intangible service depends on the customer specification demands [1]. Many people think PSS as an excellent method for enhancing competitiveness and promoting sustainability, not all PSS are sustainable. Based on $[2,3,4]$ there are three different main categories of PSS which are product -oriented, user-oriented and result -oriented.

We can define inventory as a store or stock of an object which provides specific value to an organization. Inventory management is essential to balance the organizational aim mainly for raw material and production output. Inventory management decisions can determine the future of the company. If they make a wrong decision, the company can face more significant losses. Other than that is inventory control. Inventory control will function as a monitor to monitor the stock at any point in time. In additions, there are several popular methods can be used in inventory control such as Minimum Stock Level, Stock Review, Just in Time, Economic Order Quantity (EOQ), Example, Solution, Re-order Lead Time, Batch Control and First in First out (FIFO) [4].

Nowadays, several problems happened in the oil palm industry which related to the high inventory problem. In palm oil plantation, there are several types of fertilizer with a different function for several zones which have a different number of ages of the palm oil trees. The inventory is recorded for the fertilizer, palm oil trees and all activities. The big current issue in palm oil agriculture is a lack of systematic record-keeping practices among smallholders and dealers. A study conducted on oil palm smallholders in Malaysia suggested that most oil palm companies did not have a systematic record-keeping practice which resulted in inefficiency in oil palm management [6]. In palm oil plantation, the fertilizer must be storage at a specific store will call it Greenhouse. At the Greenhouse areas are contained concentrated nutrients that must be stored and managed (Agriculture Environmental Management, AEM). Fertilizer can cause harm if they reach surface or ground water. Excessive nitrate concentrations in drinking water can cause health risks in young children. Phosphorus can be transported to surface waters and cause algae blooms and eutrophication; resulting in poor water quality [7]. Storing fertilizers separate from other chemicals in dry conditions can minimize these risks. Extra care needs to be given to concentrate stock solutions. Secondary containment should always be used. Untimely application of fertilizer leads to excessive release from the production system to surface and or ground water. Potential problems can be minimized through adequate environmental awareness, employee training, and emergency preparedness.

Other than that, high inventory of fertilizer sapling of palm oil tree also happened in the palm's nursery oil plantation. The most significant factor of this problem happened is when the replanting program had been postponed. Sapling of the palm oil trees required good care to avoid it died. If the time of replanting program postpones for a long time, it will increase the amount of sapling and reduce the spacing in the nursery. To ensure all the sapling get proper care, worker is needing, and this will increase the amount of cost to pay worker. The fresh fruit bunches (FFB) high inventory problem happened when delivering the process of the FFB to the factory was disrupted because of technical problems. Based on the policies of the plantation company, to maintain the freshness of the fruit, the fresh fruit bunches must be delivered to the factory within 24 hours, than when the delivery delay over 24 hours can be make the fruit is crushed, the less FFA is formed, the better the yield and quality of CPO $[8,9,10]$.

\section{METHODOLOGY}

There are several main steps in order to develop the inventory record application system. The first step was the preliminary streak required to gain and assemble data to implement and perform task needed for Product-Service System (PSS) Inventory Control. The information gathered will be used as basis for further system development, where details are formed and composed by referring to earlier research, enabling further details development and consignment to the next stage of the research. This project research is started by two vital information, called as Pre-arrangement and Ordering. Pre-arrangement is where initial information is collected, as introduction before ordering part. These pre-arrangement items is required before further research could be undertaken as each required information must be in scope and narrowed, as not to far as become non-realistic. Ordering is where initial information is reviewed, as Project Scope, Project Objective, Project Aims and Project Limitation. These four pre-arrangement items are important to further control the view of the project. Full analysis of the work will be consisted system required to achieve final software development. The software programming will be performed using Personal Computer (PC) based system, in the Windows Operating System (OS). The selection of the system will require Integrated Development Environment (IDE) supporting such a system (i.e. Microsoft Visual Basic 6). As the system also need storage system, Microsoft Access Database (MDB) is selected as the device which respond with programming IDE selected. In performing such programming, many methods and techniques will be 
discussed as programming mush be correct and free of mistakes that will lead programming to crash. Such action is called debugging, which is important to provide free hassle executable system and out of errors such as memory management and runtime problems.

\section{RESULT AND DISCUSSION}

A program is designed to keep and manage all information retrieved from to Company $\mathrm{A}$. The programming used in Microsoft Visual Basic 6 as to get maximum compatibility for computer used in the Company A. The computer used in the company is an IBM Personal Computer (PC) compatible system, having Microsoft Windows 7 Operating System (OS) 64-bit with x64 compatible processor (Intel). Comparison is taken for Microsoft NET system versus old Native code system, where Microsoft NET requires many configurations based on which NET programming version is used, while each runtime require $100 \mathrm{MB}$ or more compared to $2 \mathrm{MB}$ native runtime. The programming structure in Microsoft Visual Basic 6 could be defined in Figure 1 below having prjDegr.vbp as the main holder of the code and modMain.bas as the loader.

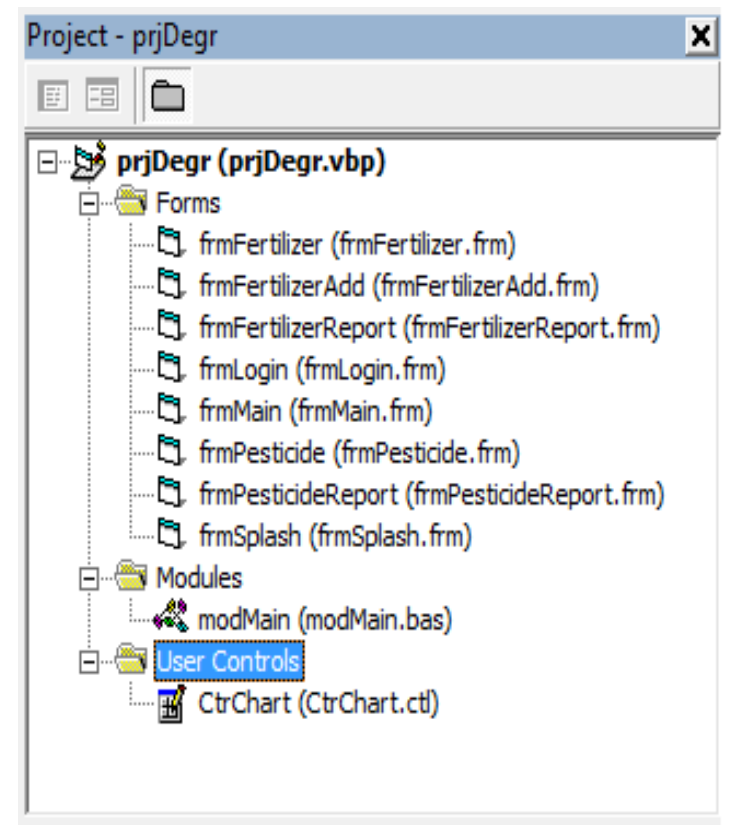

Figure 1 : Programming Structure (VB6 Programming Mode)

The login screen (frmLogin.frm) accessing password stored into the same database. A Guide User Interface (GUI) is used to show username and password textbox, where correct information must be supplied to gain entrance. The password textbox is set to asterisk to prevent eavesdropping and not allowed copy and paste using software snooping method. After the program is supplied with correct credentials, with included username and password, a splash screen (frmSplash.frm) is generated to load any program requirements and needs. In this form, program will load Microsoft JET Engine OLE Database 4.0, connected to local datapath and local file (datas.mdb). The connection is applied using adOpenKeyset and adLockOptimistic method, where adOpenKeyset react as a dynamic keyset, which is keyset cursor, where data record could be accessible but not to new key addition by other user. Method adLockOptimistic implements optimistic locking, where data required checking and updating using Update method. The chart control (ctrChart.ctl) is also loaded during the same time. After the program is loaded successfully, the main program is supplied as per Figure 2, where two (2) buttons are supplied at the left side, namely Fertilizer and Pesticide. A button on the down left, namely Exit is left for user for allowed user to quit the program if necessary. 


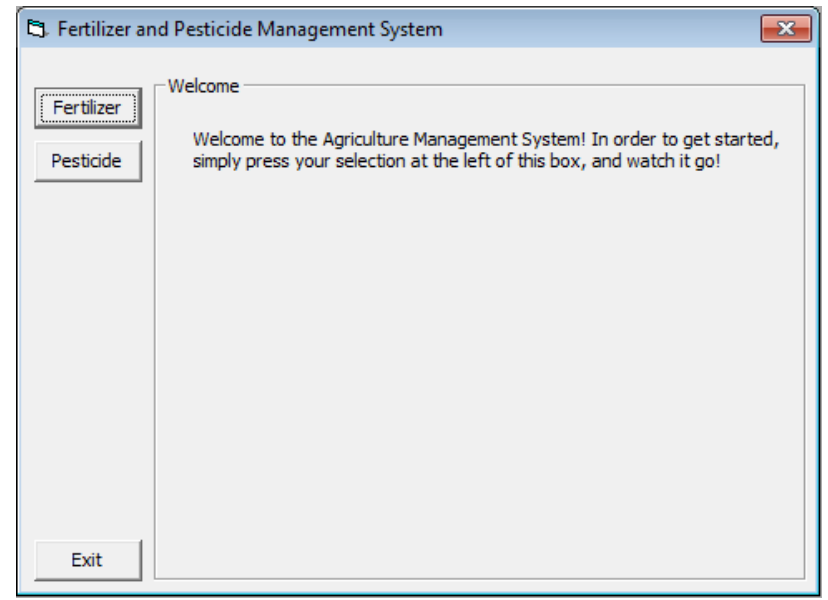

Figure 2: Main Screen

The form is designed to contain information gathered from fertilizer data from Company A, having list of block ID setting into place corresponding to palm plot in the Company A's farm. Each information should detail the area size in acre, SPA (number of palm per acre), NK, Mix A, Kierserate, Cirp, Compound 25 and Borate Fertilizer dose. The form is loaded using vbModal style as in Figure 3 where no additional form utilized during form load.

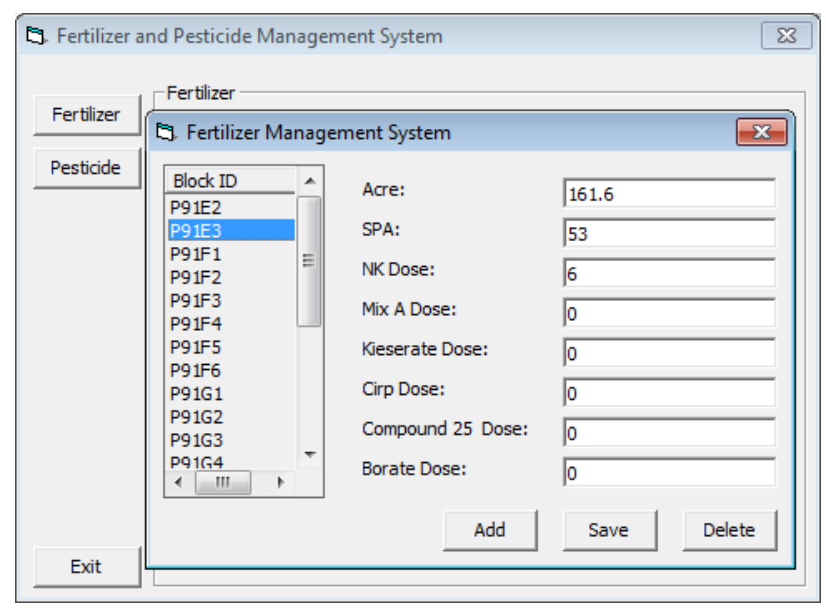

Figure 3: Fertilizer Management System (frmFertilizer.frm)

In the pesticide configuration (frmPesticide.frm), a list of pesticide used in the farm is filled in the database. Each pesticide is detailed to name, manufacturer, composition and item stock. The item stock is used to set in and out of each pesticide used and received from supplier, where each tracking is logged. Pesticide item can be maneuvered by clicking ComboBox highlighted on Figure 4.

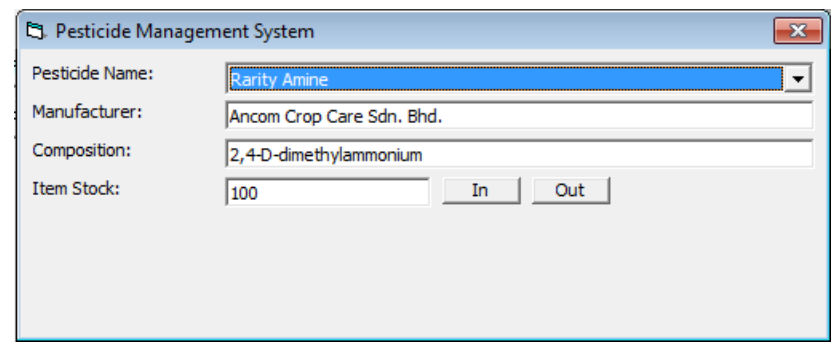

Figure 4: Pesticide Management System 


\section{Fertilizer and Pesticide Report}

After all data is entered and recorded into the database, a reporting system (frmFertilizerReport.frm) will demonstrated into series of graph, projected by CtrChart.ctl, where sequences of graph drawn using GradientFill Application Programming Interface (API) msimg32.dll, ColorAdjustLuma shlwapi.dll and CreateFont gdi32.dll. The full form is shown as per Figure 5, in the Fixed Single border style. The interactive interface is applied using selective MouseMove, where action is performed while mouse pointer hovering over the form itself. Figure 15 for fertilizer and Figure 16 for pesticide shows the form action while mouse hovering on the form.

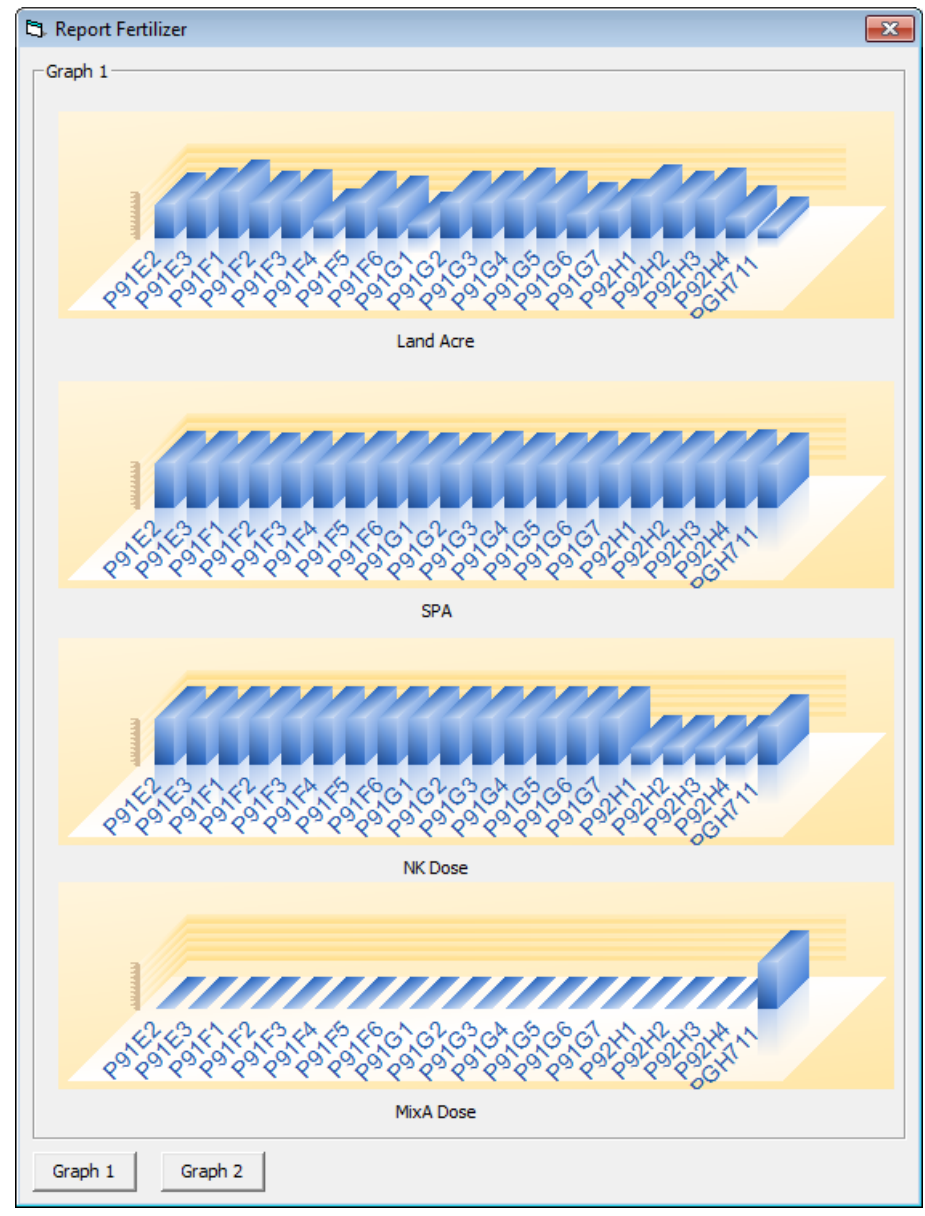

Figure 5:Fertilizer Reporting Form

\section{CONCLUSIONS}

As the conclusion of this research, based on the interview session and observation with the top management in the palm oil plantation company, all the characteristic operations and inventory information of the palm oil plantation were successfully collected. The observation at all main operating processes of palm oil plantation with fully guided by the top management staffs make the process of collecting and recording relevant information more accessible and more apparent. The primary purpose of development of this inventory application system is to help and to improve the management of inventory control system for Palm Oil Plantation Company. All the tools required for the PSS inventory control had combined in one application which consists of tools of inventory record system. With the use of the online database, the data storage of the inventory objects would be enlarged, together with the better-enhanced security and quicker handling. Other than that, this inventory 
application system also would help the management in decision and calculation making. Thus, much time can reduce by using this inventory record application system.

This inventory record system makes it easier for companies to keep track of their used fertilizer and pesticide records. This inventory record system also enhances the efficiency of management work. This record system can also be used to record information about company assets such as furniture, office equipment, and existing machinery and so on. The use of this record system can further enhance a company's record system during the audit. In implementing the audit process, the company only needs to attach a report analysis section. All the information obtained from the analysis report is detailed and easy to understand by the auditor.

\section{REFERENCES}

[1] Tukker, A. (2004). Eight Types Of Product -Service System: Eigth Ways To Sustainability? Experiences From Suspronet., 260, 246-260.

[2] Goedkoop, M.J., van Halen, C.J.G., te Riele, H.R.M. and Rommens, P.J.M. (1999) Product Service System, Ecological and Economic Basic. The Report No. 1999/36.

[3] Tracy, B., J.Hernandez, R., Rapitsenyane, Y., \& Trimingham, R. (2018) Product Service Systems. A Sustainable Design Strategy for SMEs in the Textiles and Leather Sectors.

[4] Manzini, E., \& Vezzoli, C. (2003). A Strategic Design Approach to Develop Sustainable Product Service Systems: Examples taken from the 'Environmentally Friendly Innovation'.

[5] Muhammad Barwa, T. (2015). Inventory Control as an Effective Decision-Making Model and Implementations for Company's Growth. International Journal of Economics, Finance and Management Sciences.

[6] Engler, A and Toledo, R (2010). An Analysis of factors affecting the adoption of economic and productive data recording methods of Chilean farmers. Ciencia e Investigation Agraria, 37 (2): 101-109

[7] Woittiez, L. S., Turhina, S., Deccy, D., Slingerland, M., van Noordwijk, M., Giller, K. E. (2018). Fertiliser application practices and nutrient deficiencies in smallholder oil palm plantations in Indonesia. Experimental Agriculture (2018): 1-17.

[8] Alimalbari, A., Hanifarianty, S., Kumar, A., \& Khomphet, T. (2019). Effects of Pressed Palm Conditions on Acceleration of Palm Drying Rate and CPO Quality. 1(1), 12-19.

[9] Nabila Farhana Jamaludin, Haslenda Hashim, Zarina Ab Muis, Zaki Yamani Zakaria, Mazura Jusoh, Alafiza Yunus \& Siti Mariah Abdul Murad (2018). A sustainability performance assessment framework for palm oil mills. Journal of Cleaner Production.

[10] Kushairi . A, Singh. R \& Ong-Abdullah. (2017). The Oil Palm Industry In Malaysia: Thiring With Transformation Technologies. 